\title{
Stem cells: Perspectives for the pig in relation to other species
}

\author{
Stoyan Petkov \\ Friedrich Loeffler Institute, Institute for Farm Animal Genetics, Mariensee, Germany
}

The derivation of pluripotent stem cells from mouse and human embryos and the reprogramming of somatic cells into induced pluripotent stem cells (iPSC) has initiated a new era of research in the field of regenerative medicine. The need for these cells to be tested in relevant animal models, as well as their potential to be used in the genetic engineering of livestock, has generated significant interest in the establishment of pluripotent stem cell lines from farm animals, including from the porcine species. Despite that to date no true porcine pluripotent stem cell lines have been established from cultured embryonic stem cells, there have been some significant advances in the area of iPSC and mesenchymal stem cells. This review examines the current state of porcine stem cell culture, with focus on the challenges that still need to be overcome in order to allow the wider use of these cells in biomedical models or in the field of animal biotechnology.

\section{Introduction}

The early embryonic development in all vertebrates begins with the totipotent zygote (which can form all the embryonic and placental tissues), and proceeds in highly organized and controlled fashion whereupon the ability of most cells to form multiple cell types is lost during the process of differentiation. At blastocyst stage, a relatively small group of cells, named inner cell mass (ICM), has retained the capability of specializing into all embryonic lineages but is not able to form the placenta, and is therefore designated as pluripotent. This characteristic is lost in most cells after the onset of gastrulation, where the main germ layers are formed. From this stage on, pluripotency (as induced in certain in vitro conditions) is retained in the germ line (primordial germ cells (PGC) and spermatogonial stem cells (SSC)), while throughout the somatic tissues many cells preserve the capability to form a limited number of different cell types (multipotency) and serve mainly as a source of tissue renewal (the so-called adult, or somatic, stem cells).

The preservation and maintenance of the pluripotent or multipotent characteristics of stem cells in vitro has been a subject of intense research. In 1981, two groups reported the establishment on the first murine embryonic stem cell (ESC) lines from cultured ICM (Evans \& Kaufman 1981, Martin 1981). Seventeen years later, James Thompson and co-workers reported the establishment of the first human ESC (Thompson et al. 1998). Usually, the term "ESC" applies for pluripotent cells isolated from ICM in vitro; however, embryonic cells with pluripotent potential have been derived also from mouse embryos at later stages, such as epiblast stem cells (EpiSC) (Brons et al. 2007, Tesar et al. 2007). These cells resembled human rather than mouse ESC in their morphology and culture requirements, and could not form chimeras despite their ability to form teratomas in immunodeficient mice. 
Another type of pluripotent embryonic stem cells that has been established are the so-called embryonic germ cells (EGC), which are derived from cultured PGC obtained from fetuses (Matsui et al. 1992, Resnick et al. 1992). An interesting fact in this case is that murine PGC do not seem to possess pluripotency, since they have failed to produce chimeras (Stewart et al. 1994) and to differentiate into different cell types in vitro. However, when cultured for certain time in the presence of leukemia inhibitory factor (LIF), stem cell factor (SCF), and basic fibroblast growth factor (bFGF), mouse PGC can become epigenetically reprogrammed to pluripotency (Durcova-Hills et al. 2008) and are able to form germ line chimeras (Labosky et al. 1994). The establishment of human EGC-like lines has also been reported (Shamblott et al. 1998; Turnpenny et al. 2005); however, these cells are not considered to be equivalent to their mouse counterparts due to their limited ability to differentiate in vitro and inability to form teratomas.

Lastly, stem cells with pluripotent characteristics have been derived from the male germ line in the neonatal (Kanatsu-Shinohara et al. 2004) and adult (Ko et al. 2009) mouse testis (designated as germ line-derived pluripotent stem cells (gPSC)). Similar cell lines have been also derived from human testicular cells (Kossak et al. 2009), but their pluripotency has not been conclusively proven. In addition, the somatic tissues of newborns and adults have been used as sources for isolation of various stem cell types, such as mesenchymal stem cells from bone marrow, umbilical cord and peripheral blood, adipose tissues, uterus, and other tissues. These cells represent heterologous cell populations with multipotent characteristics.

In 2006 - 2007, Shinya Yamanaka and his co-workers established a new milestone in modern science by reprogramming somatic cells back into pluripotency by the induced expression of pluripotency transcription factors (Okita et al. 2007, Takashi \& Yamanaka 2006). It was shown that the overexpression of only four genes, namely, Oct4, Sox2, c-myc, and KIf4, is sufficient to reprogram fibroblasts into pluripotent stem cells (called induced pluripotent stem cells (iPSC)) that are morphologically and functionally indistinguishable from ESC. This method was also efficient in the reprogramming of human somatic cells to iPSC (Takashi et al. 2007), while another group used OCT4, SOX2, NANOG, and LIN28 with similar success (Yu et al. 2007). The isolation of iPSC opened up new possibilities in regenerative medicine, since it provides opportunities for derivation of allogeneic pluripotent cells from each individual, thus reducing the risks of immunological rejection. Unlike in ESC, the derivation of iPSC does not require destruction of embryos, which circumvents a major ethical dilemma.

The isolation of ESC, iPSC, and other stem cells are major scientific achievements that have inspired hopes for finding therapies for many currently incurable illnesses and have initiated a new era of research in the regenerative medicine. However, due to the still unpredictable outcomes of pluripotent stem cell transplantation in patients, including considerable risks of tumor formations similar to teratocarcinomas, these cells need to be tested in suitable animal models before they can be used in the clinic. As a widely used farm animal with physiology and organ sizes similar to humans, the domestic pig is a particularly suitable and cost-efficient model for developing of stem cell therapies for the human medicine. In addition, the field of transgenic animal research would benefit significantly from the availability of pluripotent porcine stem cells, which are suitable for use to carry genetic modifications into germ line chimeras, thus simplifying the process of producing genetically modified pigs. Therefore, the derivation of porcine pluripotent stem cells equivalent to mouse or human ESC is an important priority in farm animal research. The purpose of this review is to examine the progress achieved in the derivation of porcine stem cells, and to comment on the problems and perspectives of this field. 


\section{Porcine embryonic stem cells}

In general, embryo-derived cell lines need to satisfy certain criteria in order to qualify as ESC, and the germ line-competent mouse ESC have been considered the "golden standard". First, these cells need to possess pluripotency as shown by the ability to differentiate into all cell types in the body. The most convincing evidence for pluripotency is the formation of chimeras with substantial contribution to all three germ layers and the germ line, either by blastocyst injection or tetraploid complementation (the latter method consists of aggregation of the pluripotent cells with tetraploid embryos, whereupon the resulting organism is derived almost entirely from the donor cells, while the tetraploid recipient cells form primarily the placenta). Another characteristic of ESC is the ability to self-renew indefinitely by symmetric division, and to preserve pluripotency and genetic stability for many numbers of divisions.

To date, no porcine ESC that satisfy all of the above criteria have been established, although the first reports on the culture of porcine blastocysts were published over 20 years ago (Evans et al. 1990, Notarianni et al. 1990, Piedrahita et al. 1990, Strojek et al. 1990). The literature on this subject has been already extensively reviewed (Brevini et al. 2008, Hall 2008, Keefer et al. 2007, Nowak-Imialek et al. 2011, Vackova et al. 2007). Overall, it has been reported that porcine ICMs can be cultured in vitro from 3-5 (Strojek et al. 1990) to as many as 80 passages (Talbot et al. 1993), although it is unlikely that the pluripotency characteristics have been preserved for the entire period of culture. Most of the reported putative porcine ESC lines have been characterized at early passages for relatively small number of pluripotency markers and have been able to differentiate into different cell types from the three germ layers in vitro; however, relatively few groups have characterized their cell lines by in vivo differentiation assays. One group had produced teratomas in nude mice (Hochereau-de Reviers \& Perreau 1993), while three groups have reported generation of chimeras by blastocyst injection (Chen et al. 1999, Gerfen \& Wheeler 1995, Vassiliev et al. 2010). The contribution of the donor cells to the three germ layers was demonstrated by the presence of coat spotting or by PCR analysis; however, no evidence for germ line chimerism has been shown. It has been estimated that the efficiency of chimera production from putative porcine ESC was low (3\% compared with $10-12 \%$ from fresh ICM (Chen et al. 1999)), while the extent of the contribution of the donor cells to the chimeric piglets has not been determined.

While chimeric contribution remains an important standard for pluripotency, some caution in interpreting the results of such assays may be required. This was shown by results from experiments where injections of fetal fibroblasts into mouse or sheep blastocysts have resulted in the formation of chimeras with contribution to all germ layers (Karasiewicz et al. 2008, Piliszek et al. 2007). When careful analysis was performed, it was determined that the mouse donor fibroblasts had formed hybrids by fusion with the recipient cells (Piliszek et al. 2007), which suggests that they may have been reprogrammed in vivo. The authors note that upon certain conditions tetraploid cells may survive and contribute to various tissues in the embryos, with the exception of the germ line (where normal ploidy is apparently essential for gamete survival). In the light of these findings, it may be necessary to analyze chimeras produced with putative porcine ESC more carefully to exclude the possibility of similar fusion reprogramming events.

Another source for pluripotent cells is the epiblast, which has been used for the isolation of mouse EpiSC. Derivation of porcine EpiSC have been reported by one group (Alberio et al. 2010). These authors showed that these cells were similar to human ESC, and depended of bFGF and Activi/Nodal signaling for maintenance of pluripotency characteristics. When induced by Bmp4 in vitro, the cells differentiated into cells from all germ layers and trophectoderm, suggesting that they may be equivalent to mouse EpiSC. No teratoma or chimera testing was carried out in order to obtain further proof of pluripotency. 


\section{Porcine embryonic germ cells}

The first report regarding the derivation of porcine EGC-like cell lines from cultured PGC using embryos at day 25 of gestation was published by Shim et al. (1997). The authors used feeder layers of irradiated mouse fibroblasts, but (unlike culture of mouse ESC) no growth factor supplements. The resulting cell lines formed compact colonies resembling murine EGC, expressed tissue non-specific alkaline phosphatase (AP), and were able to differentiate into various cell types in vitro. One chimeric piglet was produced by blastocyst injection, as verified by the presence of a spot on the skin, but germ line chimerism was not confirmed.

Following this report, other groups have reported the derivation of cell lines from cultured porcine PGC (Durcova-Hills et al. 1998, Mueller et al. 1999, Lee \& Piedrahita 2000, Petkov et al. 2008, Tsung et al. 2003). These cells have been shown to express some pluripotency markers such as AP, SSEA-1, SSEA-3, SSEA-4, and OCT4, and to be able to form embryoid body (EB)-like structures and differentiate in vitro. One group has produced chimeric piglets with overt coat chimerism (Mueller et al. 1999), and another has shown that transgenic EGClike cells expressing green fluorescent protein (GFP) contribute to all germ layers in fetuses and stillborn piglets (Piedrahita et al. 1998). No germ line chimerism has been confirmed in any of these studies, and the efficiency of generation of chimeras has been low, similarly to putative ESC cells. It was speculated that this low efficiency might be due to the inability of the putative PGC to incorporate into the rapidly developing blastocysts (Rui et al. 2004), however, attempts of these authors to improve the results by using slower-developing in vitro cultured blastocysts did not produce the desired outcome. The proliferation of the putative EGC lines has been shown to be limited to 13-54 passages as reported by different authors, and the maintenance of pluripotency over long-term has not been proven. In the light of the available results, it can be concluded that true EGC lines that are equivalent to murine EGC have not been yet established in the pig.

\section{Porcine induced pluripotent stem cells}

The establishment of mouse and human iPSC (Okita et al. 2007, Yu et al. 2007) has awakened significant interest in the reprogramming of porcine somatic cells to pluripotency using Yamanaka's methods. Within a short time from one another, three groups reported the derivation of the first porcine iPSC (Esteban et al. 2009, Ezashi et al. 2009, Wu et al. 2009). Similarly to the generation of mouse and human iPSC, the authors used lentiviral or retroviral expression of four (OCT4, SOX2, C-MYC, KLF4 (Ezashi et al. 2009, Esteban et al. 2009)), or six (OCT4, SOX2, C-MYC, KLF4, NANOG, LIN28) reprogramming factors (Wu et al. 2009) to reprogram porcine fibroblasts. The resulting cell lines formed colonies with human iPSC-like morphology, expressed endogenous pluripotency markers and were able to form EBs and teratomas.

Using similar methods, several more groups have reported generation of porcine iPSC lines during the following years (Kues et al. 2012, Liu et al. 2012, Montserrat et al. 2010, West et al. 2010). Overall, most of the porcine iPSC lines that have been reported to date have shown morphology similar to human iPSC; however, it has been shown that when the cells are cultured in medium supplemented with LIF and the protein kinase inhibitors CHIR99021 and PD0325901, they resemble mouse ESC, which are considered to be in the so-called naïve pluripotent state (Telugu et al. 2011). The pluripotency of most of the reported porcine iPSC lines have been tested by teratoma assay, but relatively few reports contain information regarding in vitro differentiation. To date, only one group has produced chimeras from iPSC derived from reprogramming of MSC (West et al. 2010), and it has shown evidence for germ line transmission (West et al. 2011). 
The potential to use porcine iPSC as model for stem cells therapies has been demonstrated by experiments where cell lines have been differentiated in vitro into retinal photoreceptors and implanted into damaged porcine retinas (Zhou et al. 2011). The successful integration of these cells suggests that they have promising potential as models for retinal regeneration. In another study, iPSC-derived porcine endothelial cells were used for transplantation in mouse myocardial models, where the experimental mice showed improvement of their cardiac function (Gu et al. 2012). Additionally, one study has shown that hepatic-like cells can be derived from putative porcine iPSC (Avaralli et al. 2012). These achievements, realized in the span of only few years, give hopes that porcine iPSC would prove to be a viable alternative to the still unavailable porcine ESC.

Despite the promising advances in this field, there are some questions that remain to be answered in order to make porcine iPSC reprogramming as efficient, reliable, and reproducible as mouse or human iPSC production. One important question is which pluripotency markers define the truly pluripotent porcine iPSC. This question arise from the finding that some lines have been shown to express SSEA-1, but not SSEA-4 (Ezashi et al. 2009), while others express SSEA-4 (Esteban et al. 2009). It has been shown that the expression of SSEA-4 is necessary for the porcine iPSC ability to differentiate into the neural lineages (Yang et al. 2012); however, it is not clear whether this marker was necessary for pluripotency. The endogenous expression of other common pluripotency markers, such as OCT4, SOX2, NANOG, REX1, LIN28, CDH1, $\mathrm{TDH}$, etc., has been used as marker for pluripotency in most porcine iPSC. Our experience shows that cell lines that express these markers still are not capable of forming teratomas and to differentiate into all three germ layer in vitro, although they can readily form trophectoderm (Petkov et al. 2013).

Another important question is regarding the optimal culture condition for the reprogramming and maintenance of the pluripotent porcine iPSC. The cell lines reported to date have been isolated in culture conditions normally used for mouse or human ESC/iPSC, and one group has produced iPSC lines without the use of any growth factors (Wu et al. 2009). Since research in the field of porcine ESC has shown that these conditions are not able to maintain pluripotency of pluripotent ICM cells in vitro, it is then pertinent to ask whether other factors are involved in the process of porcine iPSC maintenance. One such potential factor could be the continuous expression of the transgenes, which are normally silenced in mouse iPSC, but not in any of the reported porcine lines. To clarify this point, it might be necessary to generate transgene-free porcine iPSC and determine whether they preserve their pluripotency in the currently used culture conditions.

\section{Germ line-derived pluripotent stem cells}

Similarly to PGC, the unipotent germ line stem cells from the mouse testis can be converted in culture into pluripotent stem cells (gPSC) that are able to differentiate into all three germ layers in vitro and in vivo and to form germ line chimeras (Ko et al. 2009). The derivation of such cells prom the porcine testis has not been successful to date, due to the lack of optimal culture conditions. The first report of isolation and culture of A spermatogonia (Dirami et al. 1999) showed that the porcine germ line cells could survive for up to 120 hours in vitro when cultured with KSOM medium. Another group was able to sustain these cells for 9 days before they lost viability (Marret \& Durand 2000), although no information was provided regarding their pluripotent characteristics. The porcine germ line stem cells in the neonatal testis (also called gonocytes), identified by the expression of Dolichos biflorus agglutinin (DBA) antigen, have been maintained in culture for 7 days (Goel et al. 2007), have shown expression of 
pluripotency markers SSEA-1, NANOG, KLF4, DAZL, and OCT4 in culture, and have been able to form teratomas in nude mice with formation of the three germ layers (Goel et al. 2009). Nevertheless, the inability to maintain these cells in long-term culture has limited their application as stem cell models or in the field of animal biotechnology.

\section{Mesenchymal stem cells}

Pioneering studies by Friedenstein \& Petrakova (1966) first discovered the presence of MSC in rat bone marrow. Subsequent studies have identified MSC as a heterologous population of stromal cells present in a wide variety of tissues, which possess multipotent characteristics as demonstrated by their ability to differentiate into different cell types, such as bone, cartilage, epithelial, muscle, etc. (reviewed by Si et al. 2011). Similar to mouse and human, porcine MSC have been isolated by a number of research groups from bone marrow (Bosch et al. 2006, Ringe et al. 2002), umbilical cord blood (Kumar et al. 2007), peripheral blood (Wang \& Moutsoglou 2009), skin (Dyce et al. 2004, Park et al. 2012), adipose tissue (Huang et al. 2007), uterine tissues (Miernic et al. 2012), and other tissue types. Characteristic of these multipotent cells is the ability to differentiate into the osteogenic, adipogenic, and chondrogenic lineages. In addition, some groups have reported that porcine MSC can be differentiated into the endothelial (Pankajakshan et al. 2012), cardiac (Moscoso et al. 2012), and neural (Huang et al. 2007, Park et al. 2012) lineages. Characterization for cell surface antigens has shown that, similar to human, porcine MSC from bone marrow, adipose tissue and peripheral blood express CD29, CD44, CD90, CD105, but lack CD45 (Casado et al. 2012); however, there are no markers that are unique to MSC. The cell culture protocols for isolation of porcine MSC are relatively simple and reproducible, which makes them attractive alternative to ESC, where even the most complex culture conditions have not given the desired results. One problem in the culture of MSC is their limited proliferation in vitro - some of the longest-proliferating cell lines have reached approximately 100 doublings, while their differentiation potential became limited after 15 passages (Vacanti et al. 2005). This problem has been alleviated by immortalization using the pRNS-1 plasmid (Moscoso et al. 2012) or by transfection with human TERT (Wei et al. 2008).

One important characteristic of MSC is their low immunogenic profile, which accounts for lowered risk of immune rejection. This has been shown in multiple trials, where mostly allogeneic MSC have been transplanted in various tissues, including hearts, spinal cords, muscle, or cartilage in humans or mice (reviewed by Barry \& Murphy 2004). An important immunomodulating property of these cells is the ability to prevent immune rejection by suppressing lymphocyte proliferation, which has also been confirmed by studies using pig MSC (Comite et al. 2012). These results contrast the finding of another study which shows that, despite their low immunogenicity in vitro, porcine MSC can elicit immune reaction in vivo (Poncelet et al. 2007), although later the same group showed that such cells did not cause immune response when transplanted in the myocardium of fully immunocompetent porcine models (Poncelet et al. 2010). Moreover, another group has shown that transplanted bone marrow-derived MSC, together with a transient immunosuppressive treatment, modulated T-cell regulation and suppressed inflammation and graft rejection (Kuo et al. 2012). In addition, there have been multiple reports on the successful use of porcine MSC for transplantation, including more recent publications regarding the osteogenic potential of bone marrow MSC transplanted into porcine metaphyseal long-bone defect models (Herten et al. 2012), the angiogenic properties of transgenic MSC transplanted into myocardial infarction models (Lu et al. 2012), the function-restoring properties of adipose MSC in renal models (Eirin et al. 2012), etc. 


\section{Conclusions}

Despite some recent achievements in the field of iPSC and MSC culture, some major challenges remain to be overcome in order to make porcine pluripotent stem cells routinely applicable in the fields of regenerative medicine of animal biotechnology. One major challenge is to determine the molecular mechanisms of establishing and maintenance of pluripotency in porcine stem cells, which seem to be different of those in mouse and human stem cells. With improved understanding of these mechanisms, it would be possible to identify the optimal culture conditions for porcine pluripotent cells. Only then it would be possible to maintain them in long-term culture and to differentiate them into the desired cell types as necessary for testing different regenerative therapies, or to use them for the generation of transgenic pigs by chimera production.

\section{References}

Alberio R, Croxall N \& Allegrucci C 2010 Pig epiblast stem cells depend on activin/nodal signaling for pluripotency and self renewal. Stem Cells and Development 19 1627- 1636.

Aravalli R, Cressman E \& Steer C 2012 Hepatic differentiation of porcine induced pluripotent stem cells in vitro. Veterinary Journal 194 369- 374. (doi: 10.1016/j.tvjl.2012.05.013.)

Barry F \& Murphy J 2004 Mesenchymal stem cells: clinical applications and biological characterization. The International Journal of Biochemistry \& Cell Biology 36 568-584.

Bosch P, Pratt S \& Stice S 2002 Isolation, characterization, gene modification, and nuclear reprogramming of porcine mesenchymal stem cells. Biology of Reproduction 74 46- 57.

Brevini T, Antonini S, Pennarossa G \& Gandolfi F 2008 Recent progress in embryonic stem cells research and its application in domestic species. Reproduction in Domestic Animals 43 (S2) 193- 199. (doi: 10.1111/j.1439-0531.2008.01161.x.)

Brons G, Smithers L, Trotter M, Rugg-Gunn P, Sun B, Chuva de Sousa Lopes S, Howlett S, Clarkson A, Ahrlund-Richter L, Pedersen R, et al. 2007 Derivation of pluripotent epiblast stem cells from mammalian embryos. Nature 448 191- 195.

Casado J, Gomes-Mauricio G, Alvares V, Mijares J, Tarazona R, Bernad A \& Sanchez-Margallo F 2012 Comparative phenotypic and molecular characterization of porcine mesenchymal stem cells from different sources for translational studies in a large animal model. Veterinary Immunology and Immunopathology 147 104- 112. (doi: 10.1016/j. vetimm.2012.03.015.)

Comite P, Cobianchi L, Avanzini MA, Mantelli M, Achille V, Zonta S, Ferrari C, Alessiani M, De Silvestri A, Gandolfo GM, et al. 2012 Immunomodulatory properties of porcine, bone marrow-derived multipotent mesenchymal stromal cells and comparison with their human counterpart. Cellular and Molecular Biology 57 Suppl: OL1600-5.

Chen L, Shiue Y, Bertolini L, Medrano J, Bon-Durant
R \& Anderson G 1999 Establishment of pluripotent cell lines from porcine preimplantation embryos. Theriogenology 52 195- 212.

Dirami G, Ravindranath N, Pursel V \& Dym M 1999 Effects of stem cell factor and granulocyte macrophagecolony stimulating factor on survival of porcine type A spermatogonia cultured in KSOM. Biology of Reproduction 61 225- 230.

Durcova-Hills G, Prelle K, Mueller S, Stojkovic M, Motlik J, Wolf E \& Brem G 1998 Primary culture of porcine $\mathrm{PGC}$ requires LIF and porcine membrane-bound stem cell factor. Zygote 6 271- 275.

Durcova-Hills G, Tang F, Doody G, Tooze R \& Surani A 2008 Reprogramming primordial germ cells into pluripotent stem cells. PLOS ONE 3 e3531. (doi: 10.1371/journal.pone.0003531.)

Dyce P, Zhu H, Craig J \& Li J 2004 Stem cells with multilineage potential derived from porcine skin. Biochemial and Biophysical Research Communications 316 651-658

Eirin A, Zhu X, Krier J, Tang H, Jordan K, Grande J, Lerman A, Textor S \& Lerman L 2012 Adipose tissue-derived mesenchymal stem cells improve revascularization outcomes to restore renal function in swine atherosclerotic renal artery stenosis. Stem Cells 30 1030- 1041. (doi: 10.1002/stem. 1047).

Esteban M, Xu J, Yang J, Peng M, Qin D, Li W, Jiang Z, Chen J, Deng K, Zhong M, et al. 2009 Generation of induced pluripotent stem cells from Tibetan miniture pig. The Journal of Biological Chemistry 284 1764317640. (doi: 10.1074/jbc.M109.008938.)

Evans M \& Kaufman M 1981Establishment in culture of pluripotential cells from mouse embryos. Nature 292 154- 156.

Evans M, Notarianni E, Laurie S \& Moor, R 1990 Derivation and preliminary characterization of pluripotent cell lines from porcine and bovine blastocysts. Theriogenology 33 125-128.

Ezashi T, Telugu B, Alexenko A, Sachdev S, Sinha S \& Roberts M 2009 Derivation of induced pluripotent stem cells from pig somatic cells. Proceedings of the National Academy of Sciences USA 106 10993- 
10998. (doi: 10.1073/pnas.0905284106.)

Friedenstein A \& Petrakova K 1966 Osteogenesis in transplants of bone marrow cells. The Journal of Embryological Experimental Morphology $16381-$ 390.

Gerfen R \& Wheeler M 1995 Isolation of embryonic celllines from porcine blastocysts. Animal Biotechnology 6 1-14.

Goel S, Sugimoto M, Minami N, Yamada M, Kume S \& Imai H 2007 Identification, isolation, and in vitro culture of porcine gonocytes. Biology of Reproduction 77 127-37.

Goel S, Fujihara M, Tsuchiya K, Takagi Y, Minami N, Yamada M \& Imai H 2009 Multipotential ability of primitive germ cells from neonatal pig testis cultured in vitro. Reproduction, Fertility and Development 21 696-708. (doi: 10.1071/RD08176.)

Gu M, Nguyen P, Lee A, Xu D, Hu S, Plews J, Han L, Huber B, Lee W, Gong Y et al. 2012 Microfluidic single-cell analysis shows that porcine induced pluripotent stem cell-derived endothelial cells improve myocardial function by paracrine activation. Circulation Research 111 882- 893. (doi: 10.1161/ CIRCRESAHA.112.269001.)

Hall V 2008 Porcine embryonic stem cells: A possible source for cell replacement therapy. Stem Cell Reviews 4 275- 282. (doi: 10.1007/s12015-008-9040-2.)

Herten M, Grassmann J, Sager M, Benga L, Fischer J, Jäger $M$, Betsch $M$, Wild $M$, Hakimi $M$ \& Jungbluth P 2012 Bone marrow concentrate for autologous transplantation in (Göttinger) minipigs. Characterization and osteogenic potential of mesenchymal stem cells. Veterinary and Comparative Ortopaedics and Traumatology 26 (Epub ahead of print).

Hochereau-de Reviers M \& Perreau C 1993 In vitro culture of embryonic disc cells from porcine blastocysts. Reproduction, Nutrition, Development 33 475- 483.

Huang T, He D, Kleiner G, \& Kuluz J 2007 Neuron-like differentiation of adipose-derived stem cells from infant piglets in vitro. The Journal of Spinal Cord Medicine 30 S35- 40.

Kanatsu-Shinohara M, Inoue K, Lee J, Yoshimoto $M$, Ogonuki N, Miki H, Baba S, Kato T, Kazuki Y, Toyokuni S, et al. 2004 Generation of pluripotent stem cells from neonatal mouse testis. Cell 119, 1001-1012.

Karasiewicz J, Sacharczuk M, Was B, Guszkiewicz A, Korwin-Kossakowski M, Gorniewska M, Szablisty E \& Modlinski J 2008 Experimental embryonic-somatic chimaerism in the sheep confirmed by random amplified polymorphic DNA assay. The International Journal of Developmental Biology 52 315- 322. (doi: 10.1387/ijdb.072317jk.)

Keefer C, Pant D, Blomberg L \& Talbot N 2007 Challenges and prospects for the establishment of embryonic stem cell lines of domesticated ungulates. Animal Reproduction Science 98 147- 168.

Ko K, Tapia N, Wu G, Kim J, Bravo M, Sasse P, Glaser
T, Ruau D, Han D, Greber B et al. 2009 Induction of pluripotency in adult unipotent germ line stem cells. Cell Stem Cell 5 87- 96. (doi: 10.1016/j. stem.2009.05.025.)

Kossack N, Meneses J, Shefi S, Nguyen H, Chavez S, Nicholas C, Gromoll J, Turek P \& Reijo-Pera R 2009 Isolation and characterization of pluripotent human spermatogonial stem cell-derived cells. Stem Cells 27 138-49.

Kues W, Herrmann D, Barg-Kues B, Haridoss S, Nowak-Imialek M, Buchholz T, Streeck M, Grebe A, Grabundzija I, Merkert S et al. 2012 Derivation and Characterization of Sleeping Beauty TransposonMediated Porcine Induced Pluripotent Stem Cells. Stem Cells and Development (Epub ahead of print)

Kumar B, Yoo J, Ock S, Kim J, Song H, Kang E, Cho S, Lee S, Cho J, Balasubramanian S, et al. 2007 In vitro differentiation of mesenchymal progenitor cells derived from porcine umbilical cord blood. Molecules and Cells 24 343- 350.

Kuo Y, Chen C, Goto S, Huang Y, Wang C, Tsai C \& Chen C 2012 Immunomodulatory effects of bone marrowderived mesenchymal stem cells in a swine hemi-facial allotransplantation model. PLoS One. 7 :e35459 Epub 2012 Apr 25 (doi: 10.1371/journal.pone.0035459).

Labosky P, Barlow D \& Hogan B 1994 Mouse embryonic germ (EG) cell lines: Transmission through the germ line and differences in the methylation imprint of insulin-like growth factor 2 receptor (Igf2r) gene compared with embryonic stem (ES) cell lines. Development 120 3197-3204.

Lee C-K, \& Piedrahita J 2000 Effects of growth factors and feeder cells on porcine primordial germ cells in vitro. Cloning 2 197-205.

Liu K, Ji G, Mao J, Liu M, Wang L, Chen C \& Liu L 2012 Generation of Porcine-Induced Pluripotent Stem Cells by Using OCT4 and KLF4 Porcine Factors. Cellular Reprogramming 14 505- 513. (doi: 10.1089/ cell.2012.0047)

Lu F, Zhao X, Wu J, Cui Y, Mao Y, Chen K, Yuan Y, Gong D, Xu Z \& Huang S 2012 MSCs transfected with hepatocyte growth factor or vascular endothelial growth factor improve cardiac function in the infarcted porcine heart by increasing angiogenesis and reducing fibrosis. International Journal of Cardiology pii: S0167-5273(12)00827-3. (Epub ahead of print) (doi: 10.1016/j.ijcard.2012.06.052.)

Martin G 1981 Isolation of pluripotent cell line from early mouse embryos cultured in medium conditioned by teratocarcinoma stem cells. Proceedings of the Natlional Academy of Sciences USA 78 7634- 7638.

Matsui Y, Zsebo K \& Hogan B 1992 Derivation of pluripotential embryonic stem cells from murine primordial germ cells in culture. Cell 70 841- 847.

Marret C \& Durand P 2000 Culture of porcine spermatogonia: effects of purification of the germ cells, extracellular matrix and fetal calf serum on their survival and multiplication. Reproduction, Nutrition, Development 40 305- 319.

Miernik K \& Karasinski J 2012 Porcine uterus contains a 
population of mesenchymal stem cells. Reproduction 143 203- 209. (doi: 10.1530/REP-11-0202.)

Montserrat N, Bahima E, Batlle L, Häfner S, Rodrigues A, Gonzales F \& Belmonte J 2010 Generation of pig iPS cells: a model for cell therapy. Journal of Cardiovascular Translational Research 4 121- 130.

Moscoso I, Rodriguez-Barbosa JI, Barallobre-Barreiro J, Anon P \& Domenech N 2012 Immortalization of bone marrow-derived porcine mesenchymal stem cells and their differentiation into cells expressing cardiac phenotypic markers. Journal of Tissue Engineering and Regenerative Medicine 6 655-665. (doi: 10.1002/ term.469.)

Mueller S, Prelle K, Rieger N, Petznek H, Lassnig C, Luksch U, Aigner B, Baetscher M, Wolf E, Mueller $\mathbf{M}$, et al. 1999 Chimeric pigs following blastocyst injection of transgenic porcine primordial germ cells. Molecular Reproduction and Development $\mathbf{5 4}$ 244- 254.

Notarianni E, Laurie S, Moor R \& Evans M 1990 Maintenance and differentiation in culture of pluripotent embryonic cell lines from pig blastocysts. Journal of Reproduction and Fertility 41 51- 56.

Nowak-Imialek M, Kues W, Carnwath J \& Niemann H 2011 Pluripotent stem cells and reprogrammed cells in farm animals. Microscopy and Microanalysis $\mathbf{1 7}$ 474- 497. (doi: 10.1017/S1431927611000080.)

Okita K, Ichisaka T \& Yamanaka S 2007 Generation of germ line competent induced pluripotent stem cells. Nature 448 313- 317.

Pankajakshan D, Kansal V \& Agrawal D 2012 In vitro differentiation of bone marrow derived porcine mesenchymal stem cells to endothelial cells. Journal of Tissue Engineering and Regenerative Medicine (Epub ahead of print, doi: 10.1002/term.1483)

Park B, Kang D, Kang E, Byun J, Lee J, Maeng G \& Rho G 2012 Peripheral nerve regeneration using autologous porcine skin-derived mesenchymal stem cells. Journal of Tissue Engineering and Regenerative Medicine 6 113- 124.( doi: 10.1002/term.404.)

Petkov S \& Anderson G 2008 Culture of porcine embryonic germ cells in serum-supplemented and serum-free conditions: The effects of serum and growth factors on primary and long-term culture. Cloning and Stem Cells 10 263-276. (doi: 10.1089/clo.2007.0085.)

Petkov S, Hyttel P \& Niemann H 2013 The choice of expression vector promoter is an important factor in the reprogramming of porcine fibroblasts into induced pluripotent cells. Cellular Reprogramming (in press).

Piedrahita J, Anderson G \& Bondurant R 1990 On the isolation of embryonic stem cells: Comparative behavior of murine, porcine and ovine embryos. Theriogenology 34 879-901.

Piedrahita J, Moore C, Oetama B, Lee C-K, Scales N, Jagdeece R, Bazer F \& Ott T 1998 Generation of transgenic porcine chimeras using primordial germ cell-derived colonies. Biology of Reproduction $\mathbf{5 8}$ 1321-1329.

Poncelet A, Vercruysse J, Saliez A \& Gianello P 2007 Although pig allogeneic mesenchymal stem cells are not immunogenic in vitro, intracardiac injection elicits an immune response in vivo. Transplantation 83 783- 790.

Poncelet A, Hiel AL, Vercruysse J, Hermans D, Zech F \& Gianello P 2010 Intracardiac allogeneic mesenchymal stem cell transplantation elicits neo-angiogenesis in a fully immunocompetent ischaemic swine model. European Journal of Cardio-thoracic surgery 38 781787. (doi: 10.1016/j.ejcts.2010.03.035).

Piliszek A, Modlinski JA, Pysniak K, Karasiewicz J 2007 Foetal fibroblasts introduced to cleaving mouse embryos contribute to full-term development. Reproduction 133 207-218.

Resnick J, Bixler L, Cheng L \& Donovan P 1992 Longterm proliferation of mouse primordial germ cells in culture. Nature 359 550- 551.

Ringe J, Kaps C, Schmitt B, Buscher K, Bartel J, Smolian H, Schultz O, Burmester G, Haupl T \& Sittinger M 2002 Porcine mesenchymal stem cells: induction of distinct mesenchymal cell lineages. Cell and Tissue Research 307 321-327.

Rui R, Shim H, Moyer A, Anderson D, Penedo C, Rowe J, BonDurant R, Anderson G 2004 Attempts to enhance production of porcine chimeras from embryonic germ cells and preimplantation embryos. Theriogenology 61 1225-1235.

Si Y, Zhao Y, Hao H, Fu X \& Han W 2011 MSCs: biological characteristics, clinical applications and their outstanding concerns. Ageing Research Reviews 10 93-103. (doi: 10.1016/j.arr.2010.08.005.)

Shamblott M, Axelman J, Wang S, Bugg E, Littlefield J, Donovan P, Blumenthal P, Huggins G \& Gearhart J 1998 Derivation of pluripotent stem cells from cultured human primordial germ cells. Proceedings of the National Academy of Sciences USA 9513726 13731.

Shim H, Gutiérres-Adán A, Chen L-R, BonDurant R, Behboodi E \& Anderson G 1997 Isolation of pluripotent stem cells from cultured porcine primordial germ cells. Biology of Reproduction 57 1089-1095.

Strojek R, Reed M, Hoover J \& Wagner T 1990 A method for cultivating morphologically undifferentiated embryonic stem cells from porcine blastocysts. Theriogenology 33 901-913.

Stewart C, Gadi I \& Bhatt H 1994 Stem cells from primordial germ cells can reenter the germ line. Developmental Biology 161 626-628.

Talbot N, Rexroad C Jr, Pursel V \& Powell A 1993 Culturing the epiblast cells of the pig blastocyst. In Vitro Cellular and Developmental Biology. Animal. 29A 543- 554.

Takahashi K. \& Yamanaka S 2006 Induction of pluripotent stem cells from mouse embryonic and adult fibroblast cultures by defined factors. Cell 126 663-676.

Takahashi K, Tanabe K, Ohnuki M, Narita M, Ichisaka T, Tomoda K \& Yamanaka S 2007 Induction of pluripotent stem cells from adult human fibroblasts by defined factors. Cell 131 861-872.

Telugu B, Ezashi T \& Roberts M 2010 Porcine induced pluripotent stem cells analogous to naive and primed 
embryonic stem cells of the mouse. International Journal of Developmental Biology 54 1703- 1711. (doi: 10.1387/ijdb.103200bt.)

Tesar P, Chenoweth J, Brook F, Davies T, Evans E, Mack D, Gardner R \& McKay R 2007 New cell lines from mouse epiblast share defining features with human embryonic stem cells. Nature 448 196-199.

Thompson J, Itskivitz-Eldor J, Shapiro S, Waknitz M, Swiergiel J, Marshall V \& Jones J 1998 ESC lines derived from human blastocysts. Science 282 11451147.

Tsung H, Du Z, Rui R, Li X, Bao L, Wu J, Bao S \& Yao Z 2003 The culture and establishment of embryonic germ (EG) cell lines from Chinese mini swine. Cell Research 13 195- 202.

Turnpenny L, Cameron I, Spalluto C, Hanley K, Wilson D \& Hanley N 2005 Human embryonic germ cells for future neuronal replacement therapy. Brain Research Bulletin 68 76- 82.

Vacanti V, Kong E, Suzuki G, Sato K, Canty J \& Lee T 2005 Phenotypic changes of adult porcine mesenchymal stem cells induced by prolonged passaging in culture. Journal of Cellular Physiology 205 194- 201.

Vackova I, Ungrova A \& Lopes F 2007 Putative embryonic stem cell lines from pig embryos. Journal of Reproduction and Development 53 1137- 1149.

Vassiliev I, Vassilieva S, Beebe L, Harrison S, Mcllfatrick S \& Nottle M 2010 In vitro and in vivo characterization of putative porcine embryonic stem cells. Cellular Reprogramming 12 223-230. (doi: 10.1089/ cell.2009.0053.)

Wang X \& Moutsoglou D 2009 Osteogenic and adipogenic differentiation potential of an immortalized fibroblast-like cell line derived from porcine peripheral blood. In vitro Cellular and Developmental Biology. Animal. 45 584- 591. (doi: 10.1007/s11626-0099231-4.)
Wei L, Gao K, Liu P, Lu X, Li S, ChengJ, Li Y \& Lu Y 2008 Mesenchymal stem cells from Chinese Guizhou minipig by hTERT gene transfection. Transplantation Proceedings 40 547- 550. (doi: 10.1016/j.transproceed.2008.01.028.)

West F, Terlouw S, Kwon D, Mumaw J, Dhara S, Hasneen K, Dobrinsky J \& Stice S 2010 Porcine induced pluripotent stem cells produce chimeric offspring. Stem Cells and Development 19 1211- 1220. (doi: 10.1089/scd.2009.0458.)

West F, Uhl E, Liu Y, Stowe H, Lu Y, Yu P, GallegosCardenas A, Pratt S \& Stice S 2011 Brief report: chimeric pigs produced from induced pluripotent stem cells demonstrate germ line transmission and no evidence of tumor formation in young pigs. Stem Cells 29 1640- 1643.

Wu Z, Chen J, Ren J, Bao L, Liao J, Cui C, Rao L, Li H, Gu Y, Dai H, et al. 2009 Generation of pig-induced pluripotent stem cells with a drug inducible system. Journal of Molecular Cell Biology 1 46-54. (doi: 10.1093/jmcb/mjp003.)

Yang J, Mumaw J, Liu Y, Stice S \& West F 2012 SSEA4 Positive Pig Induced Pluripotent Stem Cells Are Primed for Differentiation into Neural Cells. Cell Transplantation (Epub ahead of print).

Yu J, Vodyanik M, Smuga-Otto K, Antosiewicz-Bourget J, Frane J, Tian S, Nie J, Jonsdottir G, Ruotti V, Stewart $\mathbf{R}$ et al. 2007 Induced pluripotent stem cell lines derived from human somatic cells. Science $\mathbf{3 1 8}$ 1917- 1920.

Zhou L, Wang W, Liu Y, Fernandez de Castro J, Ezashi T, Telugu BP, Roberts RM, Kaplan HJ \& Dean D 2011 Differentiation of induced pluripotent stem cells of swine into rod photoreceptors and their integration into the retina. Stem Cells 29 972- 980. 